\title{
以东亚及中亚地区虚拟湖泊水位变化为代表的 全新世有效水分变化的连续模拟
}

\author{
李育”, 张宇欣, 张新中, 叶旺庭, 徐玲梅, 韩琴, 李依婵, 刘和斌, 彭思敏 \\ 兰州大学资源环境学院, 西部环境教育部重点实验室, 干旱区水循环与水资源研究中心, 兰州 730000 \\ *通讯作者, E-mail: liyu@lzu.edu.cn
}

收稿日期：2019-06-01; 收修改稿日期：2019-12-07; 接受日期：2020-01-08; 网络版发表日期: 2020-04-01

第二次青藏高原综合科学考察研究项目(编号：2019QZKK0202)、中国科学院战略性先导科技专项项目(编号：XDA20100102)和国家自然科 学基金项目(批准号: 41822708)资助

\begin{abstract}
摘要 流域内的水量平衡可以通过单个湖泊的水位波动体现，而区域湖泊水位的一致性波动则可以反映区域有 效水分的变化. 以往的研究主要通过分析湖泊沉积物的多代用指标来重建过去的有效水分, 缺少对区域有效水分 变化的定量研究. 本研究基于瞬态气候演变模型、湖泊能量平衡模型及湖泊水量平衡模型, 以构建的虚拟湖泊为 载体, 进行东亚及中亚地区全新世以来有效水分变化的连续模拟实验. 使用的虚拟湖泊水位、面积、水深、盐度 与实际区域的湖泊状况并不相同，但能够通过假设来估算区域有效水分的相对变化. 此外，还对不同地理区域有 效水分变化的驱动机制进行了探讨. 研究结果表明: 中国北方全新世以来有效水分的逐渐降低主要受到长波和短 波辐射导致的蒸发增加, 以及夏季太阳辐射降低导致的降水减少的共同影响; 青藏高原和中亚南部全新世以来有 效水分的降低主要受控于亚洲夏季风的减弱而造成的降水减少; 而西风环流增强导致的降水逐渐增多是中亚北 部全新世晚期有效水分增加的原因.
\end{abstract}

关键词 有效水分, 虚拟湖泊, 连续模拟, 全新世, 太阳辐射

\section{1 引言}

湖泊水位记录是研究区域和全球环境变化的重要 指标(陈发虎等, 2004; Xiao等, 2004; 沈吉, 2012; Zhang 等, 2016; Zheng等, 2018). 全新世是过去气候变化研究 的重要时期, 因此研究全新世以来的湖泊演化和环境 变化对于预测未来全球气候变化具有重要意义(Innes, 1991; Davis等, 2000). 过去的几十年里, 关于呼伦湖
(Wen等，2010; Zhang等，2018)、青海湖(Madsen等, 2008; Li等，2018)、洱海(沈吉等，2004)、伊塞克湖 (Ricketts等，2001)、博斯腾湖(Wünnemann等，2006; Yao等，2018)和咸海(Boomer等，2000；Sharma等， 2018)的气候变化研究吸引了科学家们的广泛关注. 前 人的研究表明, 湖泊水位变化记录了区域有效水分的 变化, 因为它们反映了湖泊的水文平衡 ( $\mathrm{Qin}$ 和 $\mathrm{Yu}$, 1998; Anderson等, 2005, 2011; Luoto和Sarmaja-Korjo- 
nen, 2011). 湖泊的水量平衡系统是一个复杂的过程, 受到多种气候因素的制约. 但是相关的研究大多利用 地貌、沉积学和生物地层学方法重建湖泊水位、区域 有效水分和古环境. 随着古气候学的不断发展, 仅以湖 泊沉积物作为重建湖泊演化过程、水量平衡波动和古 环境变化的指标并不能更具体地解释古气候变化的机 制. 因此, 从新的角度定量重建和模拟湖泊的水文平衡 过程是十分必要的.

湖泊水位波动主要是由湖面降水、湖泊蒸发和流 域径流的变化引起的, 且这些变化受到了诸多气候及 水文过程制约. 湖泊能量平衡和水量平衡模型在很多 致力于重建湖泊水量平衡波动的研究中得到了广泛应 用(Morrill, 2004; Li和Morrill, 2010, 2013; 李育和刘媛, 2016). Qin和Yu(1998)通过引入物理量(降水量减蒸发 量)成功解释了东中亚地区末次盛冰期期间的湖泊水 位分布格局. Li和Morrill(2010)揭示了末次盛冰期期间 减少的湖泊表面蒸发量在湖泊水量平衡中发挥着重要 作用. Xue和Yu(2010)分析了30、18和6ka BP三个特征 时期有效降水和大气环流的总体格局, 得出湖泊水位 在这三个特征时期的变化主要受大气环流影响的 结论.

瞬态气候演化实验 $(\mathrm{TraCE}-21 \mathrm{ka})$ 是古气候模拟的 一种新尝试, 它能够连续模拟末次盛冰期以来的古气 候过程(He等, 2013; Cheng等, 2014). 我们使用了一系 列的模型— TraCE-21 ka模型、湖泊能量平衡模型及 湖泊水量平衡模型, 并对虚拟湖泊的水位变化进行了 连续模拟，以追溯东亚及中亚地区全新世以来区域有 效水分的变化. 同时, 将模拟结果与古气候代用指标, 如稳定性同位素 $\delta^{13} \mathrm{C} 、 \delta^{18} \mathrm{O}$ 、总有机碳( TOC)、总氮 $(\mathrm{TN})$ 和碳氮比 $(\mathrm{C} / \mathrm{N})$ 等相结合来验证区域虚拟湖泊水 位变化与气候变化的关系. 最后, 对能够直接反映气候 过程的气象要素进行趋势分析和经验正交函数分析 $(\mathrm{EOF})$, 以进一步探索虚拟湖泊水位和有效水分变化的 驱动机制.

湖泊水文平衡系统在不同的时间尺度上不断地响 应气候条件的变化. 在千年尺度上, 湖泊水位变化和温 度与区域大气环流有一定的关系，而在年际尺度上它 们则具有季节性的特征. 一个湖泊的水位变化取决于 它的水量平衡波动, 而湖表温度则与它的能量平衡波 动有关. 因此, 无论在全球还是区域范围内, 湖泊的水 文和能量状况体现了它们对气候系统能量和水文变化
的响应. 本文并不是为了模拟东亚及中亚地区特定湖 泊的能量和水量平衡过程, 而是通过假设每个陆地网 格单元都是一个独立的湖泊来模拟虚拟湖泊水位波 动, 进而完成区域有效水分对气候变化的敏感性研究. 将古气候模拟结果与古气候记录进行对比, 不仅验证 了模拟结果的真实性和准确性, 而且可以根据模拟结 果来探讨古气候记录的指示意义. 本文的目标是利用 有关水量平衡波动原因的信息来完善东亚及中亚地区 的古气候解释. 在全球变暖的背景下, 研究全新世的湖 泊演化和环境变化对于预测未来气候变化尤为重要. 本研究不仅为过去的气候变化和区域有效水分变化的 驱动机制提供了大量新的证据，而且为全面认识全新 世以来区域有效水分变化提供了新的视角.

\section{2 实验与方法}

\section{1 瞬态气候演化实验}

我们使用国家大气研究中心(NCAR)的CCSM 3 通 用气候模式完成过去 21000 年瞬态气候演化实验 (TraCE-21ka), 并建立一个虚拟的湖泊模型来连续模 拟全新世以来的有效水分变化. TraCE- $21 \mathrm{ka}$ 是一种大 气-海洋环流同步耦合模型, 提供了四维的模型数据 集. 该项目研究了大气-海洋-海冰-地表耦合的机制和 反馈, 同时可以解释过去 21000 年气候系统的演化 $(\mathrm{He}$, 2011).

TraCE-21ka基于古气候代理指标数据研究了末次 盛冰期期间的气候演化并模拟了几个突变的气候事件 (Yang等, 2015), 如地表在北大西洋地区经历了海因里 希冷事件(19 14.7ka)、波令-阿勒罗德暖事件(14.7 $12.9 \mathrm{ka})$ 以及新仙女木冷事件(12.9 11.7ka). 从深层沉 积物代理指标中重建的末次盛冰期期间的大西洋经向 翻转环流(AMOC)为气候变化提供了证据, 其表明 $\mathrm{AMOC}$ 的千年尺度变异性与包括气候突变事件在内的 气候演化是一致的(Liu等, 2009). 因此, 对表层融水通 量非常敏感的AMOC在 CCSM 3 中可以通过调节 $\mathrm{AMOC}$ 的强度和地球轨道参数对 TraCE- $21 \mathrm{ka}$ 进行模拟 (Stommel, 1961; Rahmstorf等, 2005). 由于对融水排放 的认识不足, $\mathrm{He}(2011)$ 在几次气候突变事件中, 设置融 水排放的初始条件相同、融水速度或位置不同进行了 多次实验.

CCSM 3在整个TraCE-21ka模拟过程中受到温室 
气体瞬时浓度和轨道驱动日照变化的影响. 大气中二 氧化碳 $\left(\mathrm{CO}_{2}\right)$ 、甲烷 $\left(\mathrm{CH}_{4}\right)$ 和一氧化二氮 $\left(\mathrm{N}_{2} \mathrm{O}\right)$ 的浓度 记录和辐射强迫来自Joos和Spahni(2008). 岁差、倾角 和离心率的值根据Berger(1978)设定. ICE-5G用于指定 大陆冰原以进行连续模拟，冰原面积和高度是依据 Peltier(2004)设定. 融水强迫则根据Liu等(2009)和 He (2011)设定, 植被类型被规定为现代值.

\section{2 湖泊能量平衡模型}

本文采用Hostetler和Bartlein(1990)的一维湖泊能 量平衡模型，计算了陆地上 $60^{\circ} \mathrm{E} \sim 140^{\circ} \mathrm{E}$ 和 $10^{\circ} \mathrm{N} \sim 60^{\circ} \mathrm{N}$ 所有模型网格单元的虚拟湖泊蒸发量. Morrill(2004) 利用湖泊能量平衡模型计算了湖面蒸发的年际变化, 验证了该模型在亚洲模拟中的可行性. 在该模型中,湖 面的能量平衡不仅受蒸发控制，还受水面吸收的短波 和长波辐射、水面发射的长波辐射和感热通量等能量 的控制. 当水的温度达到冰点时, 湖泊表面的能量平衡 为负, 促使冰的形成; 相反, 当湖泊表面能量平衡为正 时, 湖冰融化.

普遍假设每个湖泊为 $1 \mathrm{~m}$ 深的淡水湖，对于这个模 型则可以忽略地表水和低层水之间的能量流混合. 盐 度对饱和蒸汽压有很大的影响, 相关研究表明盐度的 增加会减少蒸发(Dickson等, 1965). 因此, 蒸发模型进 行了将湖泊深度增加到 5 和 $10 \mathrm{~m}$ 、湖泊盐度增加到 $10 \mathrm{ppt}$ 的实验 $(1 \mathrm{ppt}=1 \mathrm{ng} / \mathrm{L})$ ，结果表明湖泊深度和盐度 的不同只能改变1 $2 \%$ 的湖泊表面蒸发量. 我们的目的 并不是模拟东亚及中亚地区的实际湖泊变化，而是完 成湖泊蒸发对气候条件变化的敏感性研究，这与Hos-
tetler和Small(1999)使用假设湖泊进行影响评估的方 法类似. 湖泊深度和盐度的敏感性测试使我们确信, 对 湖泊蒸发的计算不仅针对于某一湖泊，还适用于该地 区存在的许多湖泊. 湖面能量平衡的计算公式如下 $(\mathrm{Li}$ 和Morrill, 2010):

$c_{\mathrm{w}} \rho_{\mathrm{w}} z \frac{\partial T}{\partial t}=\varphi_{\mathrm{s}}+\varphi_{\mathrm{ld}}-\varphi_{\mathrm{lu}} \pm Q_{\mathrm{e}} \pm Q_{\mathrm{h}}$,

式中, $c_{\mathrm{w}}$ 为水比热 $\left(\mathrm{J} \mathrm{kg}^{-1} \mathrm{~K}^{-1}\right), \rho_{\mathrm{w}}$ 为水体密度 $\left(\mathrm{kg} \mathrm{m}^{-3}\right), z$ 为湖泊深度 $(\mathrm{m}), T$ 为湖泊表层温度 $(\mathrm{K}), t$ 为时间 $(\mathrm{s}), \varphi_{\mathrm{s}}$ 、 $\varphi_{\mathrm{ld}}$ 分别为被水体吸收的短波和长波辐射 $\left(\mathrm{W} \mathrm{m}^{-2}\right), \varphi_{\mathrm{lu}}$ 为 湖泊发出的长波辐射 $\left(\mathrm{W} \mathrm{m}^{-2}\right), Q_{\mathrm{e}}$ 为潜热通量 $\left(\mathrm{W} \mathrm{m}^{-2}\right)$, $Q_{\mathrm{h}}$ 为感热通量 $\left.(\mathrm{W} \mathrm{m})^{-2}\right)$. 潜热通量和感热通量采用 Dickinson等(1993)公式计算:

$Q_{\mathrm{e}}=L_{\mathrm{v}} \rho_{\mathrm{a}} C_{\mathrm{D}} V_{\mathrm{a}}\left(q_{\mathrm{s}}-q_{\mathrm{a}}\right)$,

$Q_{\mathrm{h}}=C_{\mathrm{p}} \rho_{\mathrm{a}} C_{\mathrm{D}} V_{\mathrm{a}}\left(T_{\mathrm{s}}-T_{\mathrm{a}}\right)$,

式中, 下标 $\mathrm{a}$ 和 $\mathrm{s}$ 分别表示空气和地面, $L_{\mathrm{v}}$ 是汽化潜热, $\rho_{\mathrm{a}}$ 是空气密度, $V_{\mathrm{a}}$ 为风速, $q$ 为比湿, $C_{\mathrm{p}}$ 为空气比热, $T$ 为温 度, $C_{\mathrm{D}}$ 为动量阻力系数, 受控于地表粗粘度、风速及 近地面温度梯度. 湖泊中各层之间的热量垂直传递 $(z=1 \mathrm{~m})$ 是通过对流混合、浴流和分子扩散实现的. 模 型示意图如图1所示.

TraCE-21ka数据库的输入值为: $2 \mathrm{~m}$ 空气温度、地 表温度、 $2 \mathrm{~m}$ 风速、地面入射的短波和长波辐射. 湖泊 模型运行的时间步长为 $30 \mathrm{~min}$, 但是气候模型输出为连 续的月数据. 因此, 通过使用matlab中的“interp3”函数 对 TraCE-21ka输出值进行线性插值, 以达到湖泊能量 平衡模型的运行要求. 线性插值是利用已知数据点建

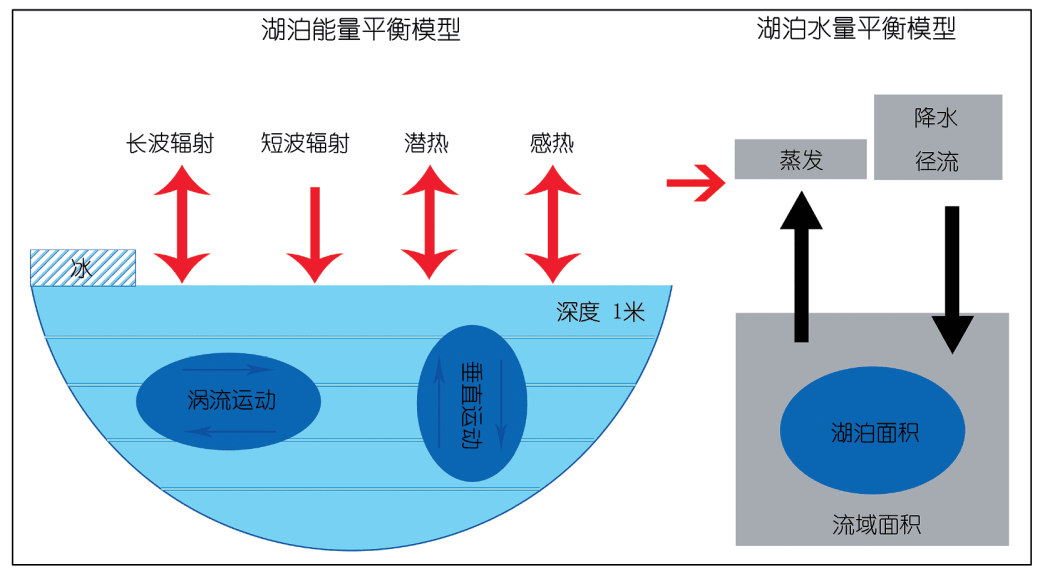

图 1 湖泊能量与水量平衡模型示意图 
立一个简单连续的未知物理量模型，进而从模型中推 断出未知物理量的特征. 已知坐标 $\left(x_{0}, y_{0}\right)$ 与 $\left(x_{1}, y_{1}\right)$, 要 得到 $\left[x_{0}, x_{1}\right]$ 区间内某一位置 $x$ 在直线上的值，计算公式 如下:

$\frac{y-y_{0}}{x-x_{0}}=\frac{y_{1}-y_{0}}{x_{1}-x_{0}}$.

由于 $x$ 值已知, 所以可以从公式(5)中得到 $y$ 的值:

$y=y_{0}+\frac{\left(x-x_{0}\right) y_{1}-\left(x-x_{0}\right) y_{0}}{x_{1}-x_{0}}$.

Morrill等(2001)实验了小时平均、天平均、月平 均等不同算法，结果显示不同算法所计算出的年湖泊 表层蒸发量之间的差别在 $3 \%$ 以内. 这是因为湖泊热量 惯性阻止了湖面蒸发随短期尺度的气象波动而发生大 的变化(Pollard和Schulz, 1994). 最后, 将TraCE-21ka输 出数据与湖泊能量平衡模型相结合，计算虚拟湖泊表 面蒸发量, 进而计算50年平均值, 并得到最终结果.

\section{3 湖泊水量平衡模型}

本文假设在CCSM 3系统中，东亚及中亚地区每 一个陆地网格为一个单独的湖泊, 每个湖泊在气候变 化过程中处于水文平衡和气候稳定状态. 这是一个合 理的假设, 因为此研究考虑到了湖泊对气候变化的响 应过程较短. 稳定条件下的湖泊水量平衡模型公式 如下:

$D=A_{\mathrm{B}} R+A_{\mathrm{L}}\left(P_{\mathrm{L}}-E_{\mathrm{L}}\right)$,

式中, $D$ 为湖泊水量的变化 $\left(\mathrm{m}^{3} \mathrm{a}^{-1}\right), A_{\mathrm{B}}$ 为流域面积 $\left(\mathrm{m}^{2}\right)$, $R$ 为流域径流量 $\left(\mathrm{m} \mathrm{a}^{-1}\right), A_{\mathrm{L}}$ 为湖泊面积 $\left(\mathrm{m}^{2}\right), \mathrm{P}_{\mathrm{L}}$ 为降水 量 $\left(\mathrm{m} \mathrm{a}^{-1}\right), E_{\mathrm{L}}$ 为湖泊蒸发量 $\left(\mathrm{m} \mathrm{a}^{-1}\right)$. 由于方程(6)对于假 想的湖泊需要 $A_{\mathrm{B}} 、 A_{\mathrm{L}}$ 确定的数值, 湖泊水位变化的过 程无法很好地计算. 因此，将该方程根据网格单元 $P_{\mathrm{L}}$ $-E_{\mathrm{L}} \geq 0$ 和 $P_{\mathrm{L}}-E_{\mathrm{L}}<0$ 进行简化. 在不提供湖泊特定信息 的情况下, 我们可以推断虚拟湖泊水位变化的方向.

不论 $A_{\mathrm{B}}$ 和 $A_{\mathrm{L}}$ 的值如何, $P_{\mathrm{L}}-E_{\mathrm{L}} \geq 0$ 网格单元代表的 湖泊是开放的湖泊(即 $D>0$ ), 开放的湖泊都会通过湖水 的排放来调节水量平衡. 公式(6)表明，如果全新世期 间 $R$ 变化和 $P_{\mathrm{L}}-E_{\mathrm{L}}$ 变化具有不同的符号, 那么 $D$ 的变化 符号将取决于湖泊特定变量 $A_{\mathrm{B}}$ 和 $A_{\mathrm{L}}$. 对于 $P_{\mathrm{L}}-E_{\mathrm{L}} \geq 0$ 的 格点, 当 $R$ 变化和 $P_{\mathrm{L}}-E_{\mathrm{L}}$ 变化在全新世期间均为正(负) 时，湖泊的水量平衡 $D$ 也为正(负). $P_{\mathrm{L}}-E_{\mathrm{L}}<0$ 的网格单 元代表的湖泊的水净损失需要径流来弥补. 这些湖泊
通过改变 $A_{\mathrm{L}}$ 与 $A_{\mathrm{B}}$ 的比值来适应水平衡的变化, 如设置 $D=0$, 计算公式如下:

$\frac{A_{\mathrm{L}}}{A_{\mathrm{B}}}=\frac{R}{\left(E_{\mathrm{L}}-P_{\mathrm{L}}\right)}$,

式中, $A_{\mathrm{L}} / A_{\mathrm{B}}$ 代表虚拟湖泊水位. 公式(7)表明, 对于封闭 的湖泊(即 $D=0$ ), $A_{\mathrm{L}} / A_{\mathrm{B}}$ 的比率不是特定于湖泊的, 而是 由气候决定的(Benson和Paillet，1989). 因此对于 $P_{\mathrm{L}}$ $-E_{\mathrm{L}}<0$ 的网格单元，我们通过计算 $A_{\mathrm{L}} / A_{\mathrm{B}}$ 的值并在模拟 中比较这些数值来确定虚拟湖泊水位的相对变化.

为了确定全新世水平衡的相对变化, 我们将 $P_{\mathrm{L}} 、 E_{\mathrm{L}}$ 和 $R$ 与公式(6)和(7)结合起来. 然后, 将水平衡相对方向 的变化归因于蒸发、降水或两者同时发生, 并寻找哪些 变量有效地促成了净水平衡的变化. 由于径流(降水减 去蒸腾)异常与降水异常高度相关，因此径流的任何生 产性贡献都被视为降水的贡献. 本研究的目的并不是 模拟东亚及中亚地区特定湖泊表面能量和水量平衡过 程, 而是利用虚拟湖泊作为载体来推断全新世区域有效 水分的变化. 进而在模拟区域平均有效水分和水文气候 条件的基础上, 探讨区域气候变化的驱动机制.

\section{4 数学建模与计算}

本文选择了经验正交函数方法(EOF)来检验湖泊 水位的时空变化. 它在 20 世纪 50 年代首次被引入进行 气象和气候研究, 现在广泛应用于其他学科. 这种方法 在前人的很多研究中已经详细介绍过(Kundu和Allen, 1976; Weare和Newell, 1977). EOF是一种分析矩阵数据 结构特征, 提取主数据特征向量的方法. 一般而言, 特 征向量对应于空间样本, 主成分对应于时间变化. 第一 个主成分倾向于描述原始时间序列的平均分布.

\section{5 古气候记录的选取标准}

本文根据以下标准总结了古气候记录: (1) 这些记 录来自湖泊沉积物或湖泊地貌证据; (2) 记录可覆盖全 新世的大部分时期且无沉积间断; (3) 从记录中得出的 代用指标应指示湖泊水位、有效水分或水文气候的 变化.

\section{3 虚拟湖泊水位模拟和古气候记录}

\section{1 模拟结果的验证}

根据气候的相似性和地形的差异性，我们将东亚 
及中亚地区划分为五个区域: 中国北部、中国南部、 中亚北部、中亚南部和青藏高原. 图2 a 显示的是文章 所收集的用以验证模拟结果的湖泊记录，更多细节详 见表1. 在考虑模型结果之前，回顾和总结全新世期间 湖泊水位的大规模模式是非常重要的. 如果模型在测 试湖泊水位变化的原因时发挥作用，那么这些模型必 须能够重现这些模式．趋势图(图2b)和时间序列(图3) 表明，在中国北部、中国南部、青藏高原及中亚南部 模拟的全新世湖泊水位呈下降趋势，而中亚北部的湖 泊水位呈上升趋势．中国南部沿海地区晚全新世高湖 面的出现则受控于海洋反馈造成的高海岸降水.

在中国北部，大部分湖泊水位在全新世早期达到 最高点，然后在全新世中期下降(表1)。这种变化模式 与模拟的湖泊水位变化趋势相似(图3a1)，表明中国北 方大部分地区的有效水分在全新世中期至晚期呈下降 趋势. 但其中也存在一些差异, 如呼伦湖水位在 $8 \sim 0 \mathrm{cal}$ $\mathrm{ka} \mathrm{BP}$ 期间上升. 在中国南部，全新世早期湖泊水位最 高, 全新世中期湖泊水位中等, 全新世晚期湖泊水位最 低, 而云贵高原在全新世晚期湖泊水位逐渐升高(表1). 模拟的区域平均水位指示中国南部湖泊的高水位不仅 出现在全新世早期，而且出现在全新世晚期前后(图 3b1); 中亚北部东侧大部分湖泊位于季风边缘带, 在全 新世中期湖泊水位较高. 而西侧地区湖泊水位受到西 风影响，晚全新世湖泊水位较高(表1). 模拟结果同样 呈现了中亚北部大部分地区的水分上升趋势(图3c1). 在青藏高原，记录和模拟的湖泊水位在全新世早期和 中期较高，并在整个全新世呈下降趋势，其变化趋势
与中亚南部相似(图3 $\mathrm{d} 1$, 图3d2), 表明气候逐渐向干燥 转变. 较少的中亚南部湖泊水位定量或定性重建的研 究成为了验证该区域模拟结果的阻碍. 根据模拟的平 均湖泊水位, 初步推测中亚南部湖泊水位变化与全新 世青藏高原湖泊水位变化一致.

此外，本文还收集了古气候记录以验证虚拟湖泊 水位是否随气候变化而变化. 记录选取的原则为指标 尽可能代表整个区域的平均气候变化. 在中国北部(图 $3 \mathrm{a} 2$ ，图3a3)，全新世中后期湖泊平均水位呈逐渐降低 的变化趋势, 与该区域的水分指数记录一致. 中国南部 的许多石笋和湖泊记录被用来揭示亚洲季风的强度、 温度和湿度的变化. 因此, 亚洲季风对中国南部水汽变 化具有重要影响. 因此, 我们从东亚季风区和印度季风 区选取基于大陆古水分记录重建的水分指标与模拟的 湖泊平均水位进行比较, 结果表明了水分记录最潮湿 的时期正与湖泊水位最高的时期相对应(图 3b2, 图 $3 b 3)$, 但是模拟的中国南部水位变化(图3b1)并不代表 亚洲季风变化，二者之间的联系还需进一步研究. 在 中亚北部(图3c2, 图3c3), 湿度指数与模型模拟的湖泊 水位变化非常接近, 在全新世晚期呈上升趋势. 青藏高 原的模拟与记录较吻合, 均表现出相似的变化规律(图 $3 \mathrm{~d} 3$, 图3d4).

\section{2 模拟湖泊水位变化与古气候记录的比较}

基于上述划分，我们选取了不同区域的典型湖泊， 并将模拟的虚拟湖泊水位与气候指标进行对比，验证 了模型的可行性和准确性. 在中国北部(图4)，全新世

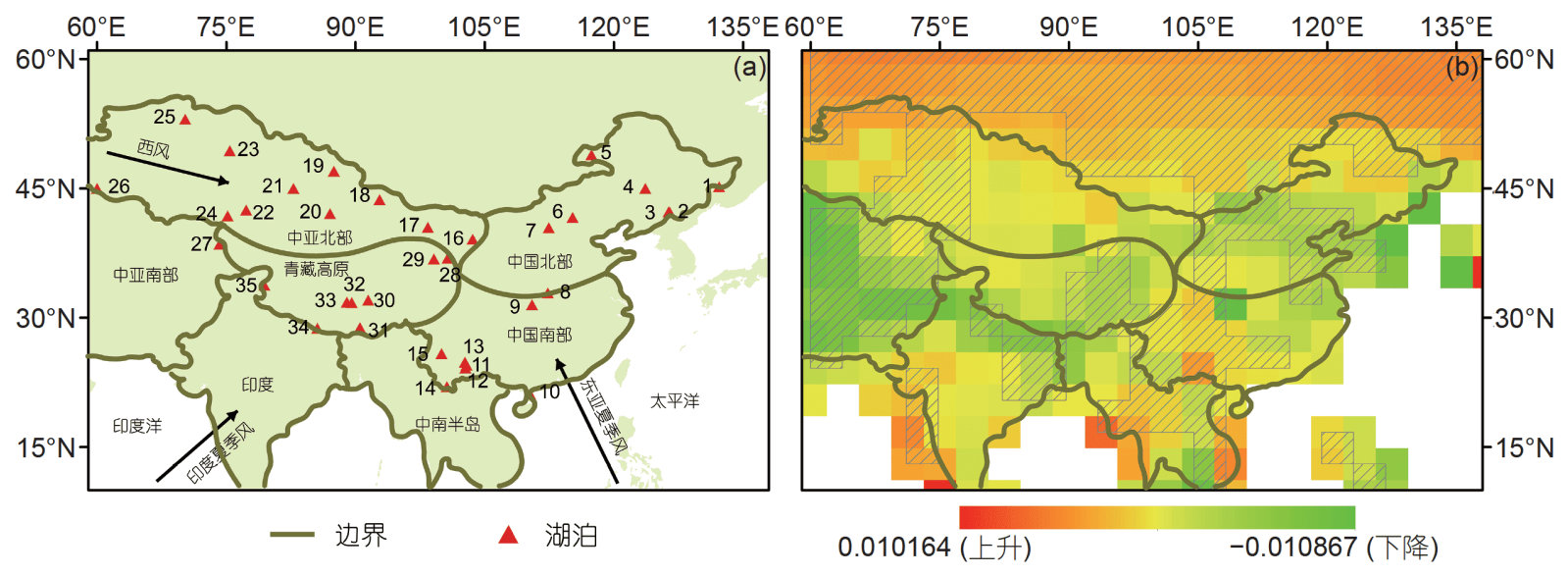

图 2 东亚及中亚地区湖泊点位置及西风、印度夏季风和东亚夏季风等环流系统(a)和全新世模拟湖泊水位的趋势分析(b) 条带表示该区域显著性检验超过 $95 \%$ 
表 1 东中亚地区全新世湖泊水位变化概况

\begin{tabular}{|c|c|c|c|c|c|c|}
\hline 区域 & 序号 & 湖泊 & 经度 & 纬度 & 全新世湖泊水位波动情况 & 参考文献 \\
\hline \multirow{7}{*}{ 中国北部 } & 1 & 兴凯湖 & $132.2^{\circ} \mathrm{E}$ & $45.2^{\circ} \mathrm{N}$ & 湖泊水位自全新世早期开始下降 & 吴健和沈吉(2010a, 2010b) \\
\hline & 2 & 哈尼湖 & $126.5^{\circ} \mathrm{E}$ & $42.2^{\circ} \mathrm{N}$ & 湖泊水位自全新世早期开始下降 & $\begin{array}{c}\text { 崔美玲等(2006); 喻春霞等 } \\
\text { (2008) }\end{array}$ \\
\hline & 3 & 二龙湾玛珥湖 & $126.36^{\circ} \mathrm{E}$ & $42.3^{\circ} \mathrm{N}$ & 湖泊水位自全新世早期开始上升 & $\begin{array}{c}\text { 游海涛和刘嘉麒(2012); } \\
\text { Wang等(2012) }\end{array}$ \\
\hline & 4 & 大布苏湖 & $123.65^{\circ} \mathrm{E}$ & $45^{\circ} \mathrm{N}$ & 湖泊水位自全新世早期开始上升, 然后下降 & 沈吉等(1998); 介冬梅等(2001) \\
\hline & 5 & 呼伦湖 & $117.4^{\circ} \mathrm{E}$ & $48.9^{\circ} \mathrm{N}$ & 湖泊水位自全新世早期开始下降, 随后上升 & $\begin{array}{l}\text { Wen等(2010); } \\
\text { Xiao等(2009) }\end{array}$ \\
\hline & 6 & 巴彦查干湖 & $115.21^{\circ} \mathrm{E}$ & $41.65^{\circ} \mathrm{N}$ & 湖泊水位自全新世早期开始上升, 然后下降 & Jiang等(2006) \\
\hline & 7 & 岱海 & $112.45^{\circ} \mathrm{E}$ & $40.45^{\circ} \mathrm{N}$ & 湖泊水位自全新世早期开始上升, 然后下降 & Sun等(2009); Xiao等(2004) \\
\hline \multirow{8}{*}{ 中国南部 } & 8 & 龙泉湖 & $112.33^{\circ} \mathrm{E}$ & $32.87^{\circ} \mathrm{N}$ & 湖泊水位自全新世早期开始上升, 然后下降 & 李文漪和姚祖驹(1993) \\
\hline & 9 & 大九湖 & $110.5^{\circ} \mathrm{E}$ & $31.5^{\circ} \mathrm{N}$ & 湖泊水位自全新世早期开始下降 & 马春梅等(2008) \\
\hline & 10 & 湖光岩玛珥湖 & $110.28^{\circ} \mathrm{E}$ & $21.15^{\circ} \mathrm{N}$ & 湖泊水位自全新世早期开始下降 & Wu等(2012) \\
\hline & 11 & 星云湖 & $102.88^{\circ} \mathrm{E}$ & $24.5^{\circ} \mathrm{N}$ & 湖泊水位自全新世早期开始下降 & Hodell等(1999) \\
\hline & 12 & 杞麓湖 & $102.75^{\circ} \mathrm{E}$ & $24.17^{\circ} \mathrm{N}$ & 湖泊水位自全新世早期开始下降, 随后上升 & Brenner等(1991) \\
\hline & 13 & 滇池 & $102.7^{\circ} \mathrm{E}$ & $24.85^{\circ} \mathrm{N}$ & 湖泊水位自全新世早期开始下降, 随后上升 & Zhang等(2009) \\
\hline & 14 & 曼兴湖 & $100.6^{\circ} \mathrm{E}$ & $22^{\circ} \mathrm{N}$ & 湖泊水位自全新世早期开始下降 & 唐领余(1992) \\
\hline & 15 & 洱海 & $99.98^{\circ} \mathrm{E}$ & $25.84^{\circ} \mathrm{N}$ & 湖泊水位自全新世早期开始下降, 随后上升 & 周静等(2003) \\
\hline \multirow{11}{*}{ 中亚北部 } & 16 & 青土湖 & $103.6^{\circ} \mathrm{E}$ & $39.1^{\circ} \mathrm{N}$ & 湖泊水位自全新世早期开始上升, 然后下降 & 赵强等(2005) \\
\hline & 17 & 花海 & $98.4^{\circ} \mathrm{E}$ & $40.5^{\circ} \mathrm{N}$ & 湖泊水位自全新世早期开始下降 & 胡刚等(2003) \\
\hline & 18 & 巴里坤湖 & $92.8^{\circ} \mathrm{E}$ & $43.7^{\circ} \mathrm{N}$ & 湖泊水位自全新世早期开始上升, 然后下降 & Zhao等(2015) \\
\hline & 19 & 乌伦古湖 & $87.5^{\circ} \mathrm{E}$ & $47^{\circ} \mathrm{N}$ & 湖泊水位自全新世早期开始下降, 随后上升 & Liu等(2008a) \\
\hline & 20 & 博斯腾湖 & $87.05^{\circ} \mathrm{E}$ & $42.08^{\circ} \mathrm{N}$ & 湖泊水位自全新世早期开始下降, 随后上升 & Wünnemann等(2006) \\
\hline & 21 & 艾比湖 & $82.8^{\circ} \mathrm{E}$ & $45^{\circ} \mathrm{N}$ & 湖泊水位自全新世早期开始下降 & Wang等(2013) \\
\hline & 22 & 伊塞克湖 & $77.30^{\circ} \mathrm{E}$ & $42.50^{\circ} \mathrm{N}$ & 湖泊水位自全新世早期开始下降, 随后上升 & $\begin{array}{c}\text { Ricketts等(2001); Ferronskii等 } \\
\text { (2003) }\end{array}$ \\
\hline & 23 & Pashennoe & $75.40^{\circ} \mathrm{E}$ & $49.37^{\circ} \mathrm{N}$ & 泊水位自全新世早期开始下降, 随后上升 & Tarasov和Kremenetskii(1995) \\
\hline & 24 & Sonkel & $75.15^{\circ} \mathrm{E}$ & $41.82^{\circ} \mathrm{N}$ & 湖泊水位自全新世早期开始下降, 随后上升 & Sevastyanov和Smirnova(1986) \\
\hline & 25 & Karas'e & $70.22^{\circ} \mathrm{E}$ & $53.03^{\circ} \mathrm{N}$ & 湖泊水位自全新世早期开始下降, 随后上升 & Tarasov和Kremenetskii(1995) \\
\hline & 26 & 咸海 & $60^{\circ} \mathrm{E}$ & $45^{\circ} \mathrm{N}$ & 湖泊水位自全新世早期开始上升, 然后下降 & Boomer等(2000) \\
\hline 中亚南部 & 27 & Rangkul-Shorkul & $74.20^{\circ} \mathrm{E}$ & $38.52^{\circ} \mathrm{N}$ & 湖泊水位自全新世早期开始上升, 然后下降 & Sevastyanov和Dorofeyuk(1992) \\
\hline \multirow{8}{*}{ 青藏高原 } & 28 & 青海湖 & $100.7^{\circ} \mathrm{E}$ & $36.9^{\circ} \mathrm{N}$ & 湖泊水位自全新世早期开始上升, 然后下降 & Madsen等(2008) \\
\hline & 29 & 茶卡盐湖 & $99.1^{\circ} \mathrm{E}$ & $36.8^{\circ} \mathrm{N}$ & 湖泊水位自全新世早期开始上升, 然后下降 & Liu等(2008b) \\
\hline & 30 & 措那湖 & $91.47^{\circ} \mathrm{E}$ & $32.03^{\circ} \mathrm{N}$ & 湖泊水位自全新世早期开始上升, 然后下降 & 吴中海等(2005) \\
\hline & 31 & 沉错 & $90.52^{\circ} \mathrm{E}$ & $28.85^{\circ} \mathrm{N}$ & 湖泊水位自全新世早期开始上升, 然后下降 & Zhu等(2009) \\
\hline & 32 & 班戈错 & $89.57^{\circ} \mathrm{E}$ & $31.75^{\circ} \mathrm{N}$ & 湖泊水位自全新世早期开始下降 & 赵希涛等(2001) \\
\hline & 33 & 色林错 & $89^{\circ} \mathrm{E}$ & $31.8^{\circ} \mathrm{N}$ & 湖泊水位自全新世早期开始上升, 然后下降 & Li等(2009) \\
\hline & 34 & 佩枯措 & $85.58^{\circ} \mathrm{E}$ & $28.78^{\circ} \mathrm{N}$ & 湖泊水位自全新世早期开始下降 & 边彦明等(2013) \\
\hline & 35 & 班公错 & $79.42^{\circ} \mathrm{E}$ & $33.77^{\circ} \mathrm{N}$ & 湖泊水位自全新世早期开始上升, 然后下降 & Rossit等(1996) \\
\hline
\end{tabular}



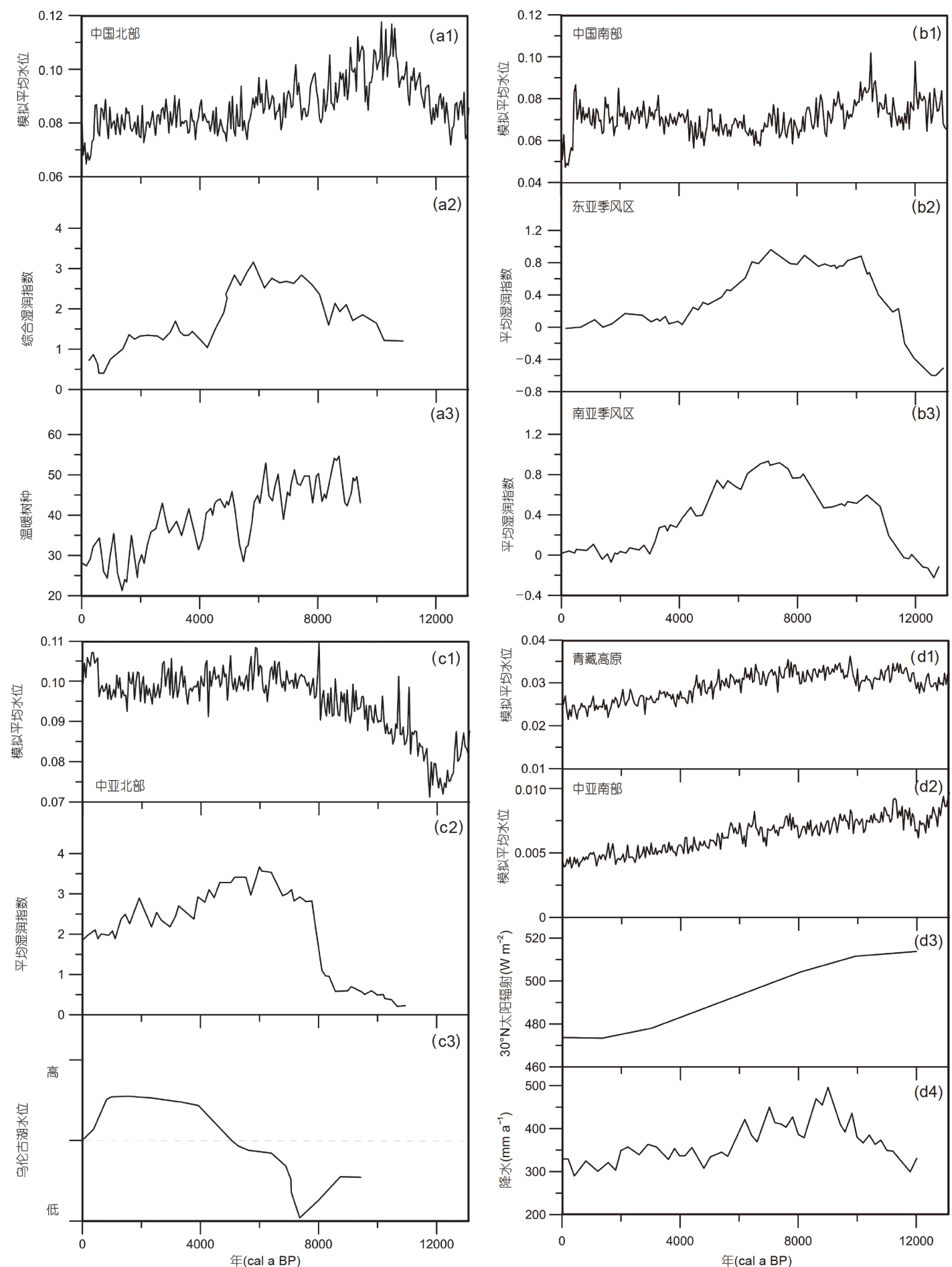

图 3 全新世不同地区模拟的平均湖泊水位与古气候记录对比

(a1) 中国北部模拟的平均水位; (a2) 由中国北方东亚夏季季风降雨带合成的花粉型水分指数(Wang和Feng, 2013); (a3) 中国北方镜泊湖温暖落 叶阔叶树种变化(Li等, 2011); (b1) 中国南方模拟的平均水位; (b2)和(b3)基于东半球大陆古水分记录的东亚夏季风和印度夏季风区水分指数 (Wang等, 2017); (c1) 中亚北部模拟的平均水位; (c2) 根据中亚干旱区湖泊记录计算的平均湿度指数(安成邦和陈发虎, 2009); (c3) 根据乌伦古 湖的粒度和花粉数据重建的湖泊水位波动(Liu等, 2008a); (d1) 青藏高原地区模拟平均水位; (d2) 中亚南部模拟平均水位; (d3) 全新世 $30^{\circ} \mathrm{N}$ 附 近的夏季太阳辐射(Berger和Loutre, 1991); (d4) 青藏高原地区重建的全新世降水(侯光良等, 2012) 


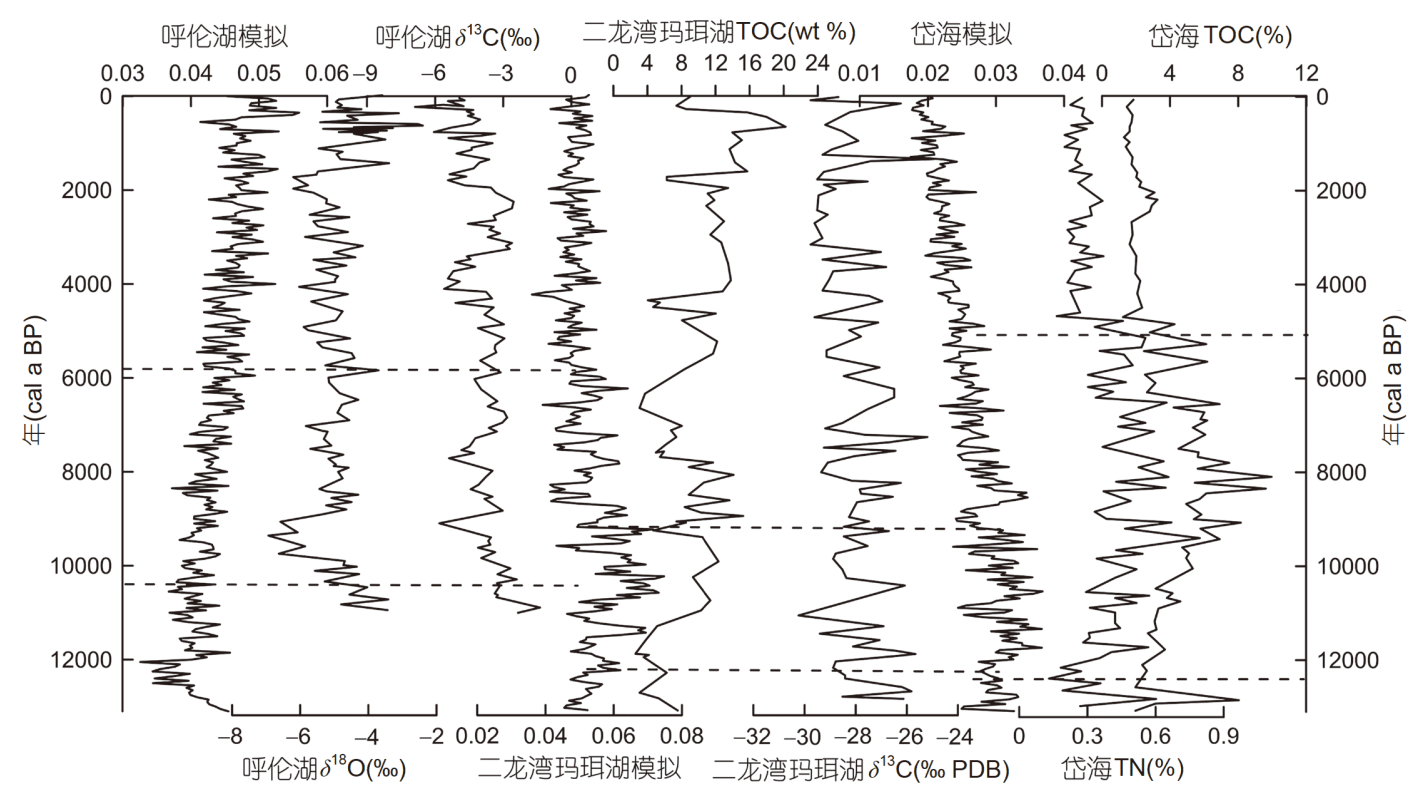

图 4 全新世中国北部模拟的典型湖泊水位与古气候记录对比

由左至右对应的曲线为: 呼伦湖模拟的水位; 呼伦湖的 $\delta^{18} \mathrm{O}$ 和 $\delta^{13} \mathrm{C}\left(\mathrm{Zhai}\right.$ 等, 2011); 二龙湾玛珥湖模拟的水位; 二龙湾玛珥湖的 $\mathrm{TOC}$ 和 $\delta^{13} \mathrm{C}($ 游海 涛和刘嘉麒, 2012); 岱海湖模拟的水位; 岱海的 TN和TOC(Sun等, 2010)

早期形成了许多内陆湖泊, 主要受亚洲季风影响. 选取 了中国北部自东至西的二龙湾玛珥湖、呼伦湖和岱海 湖进行了模拟, 并且它们都有连续的古环境记录. 呼伦 湖模拟呈现稳定上升趋势，波动不大。在10000 $6000 \mathrm{cal}$ a BP间低的 $\delta^{18} \mathrm{O}$ 和 $\delta^{13} \mathrm{C}$ 值指示了呼伦湖在此期 间的高水位. 此外, 在3350 1190 cal a BP发生了湖泊水 位显著上升的情况. 二龙湾玛珥湖的模拟效果较好, 与 古气候记录相吻合，均表现出全新世早期的湿润环境. 良好的气候条件有利于 TOC和TN的积累，可以间接反 映环境信息。岱海早、中全新世湖泊水位升高与 TOC、TN波动具有良好的一致性.

中国南部的长江中下游地区在全新世早期没有大 规模的湖泊发育, 仅出现了一些零星的湖相沉积, 如固 城湖(江苏省)等(沈吉, 2012). 因此, 我们选取形成时间 较早且具有连续演化过程的星云湖、洱海和滇池来分 析湖泊水位的变化(图5). 由于受到新仙女木冷事件的 影响，三个湖泊的模拟结果均在13100 12000 cal a BP 呈现一个较低的湖泊水位. 之后, 气候转暖, 滇池、洱 海在全新世早期开始扩张, 水位升高, 在全新世中期开 始缓慢下降, 在 $4000 \mathrm{cal}$ a BP至现代呈现上升的状态. 此外, 滇池的稳定性同位素正(负) $\delta^{13} \mathrm{C}$ 值代表一个相对 干旱(潮湿)环境. 根据滇池各指标和湖泊水位的变化,
两者均呈现了相似的变化趋势(图5). 然而, 星云湖水 位并没有大的波动，整体上从早全新世向晚全新世稳 定下降, $\delta^{18} \mathrm{O}$ 所指示的环境变化与模拟结果呈现类似 的模式.

结合青藏高原的区域特征，对青藏高原自东向西 分布、具有连续古气候记录的沉错、色林错和班公错 三个湖泊进行了对比分析(图6). 气候指标与前几节使 用的指标一致. 三个湖泊的水位具有相似的变化趋势: 在 $12000 \sim 6000 \mathrm{cal} \mathrm{a} \mathrm{BP}$ 有明显的上升趋势，在 6000 2000 cal a BP期间, 湖泊水位开始逐渐下降, 并 在现代呈微上升趋势. 沉错的古气候指标与模拟湖泊 水位变化曲线具有较好的一致性，指示4000 8000 cal a BP期间较高湖泊水位与 TOC、 TN指示的全新世中 期湿润气候条件相对应. 班公错偏低的 $\delta^{18} \mathrm{O}$ 和偏负的 $\delta^{13} \mathrm{C}$ 值指示潮湿的环境与高湖面均出现在早中全新世 期间. 虽然色林错的气候指标波动不大, 但其与模拟曲 线的变化趋势是一致的. 较低的 $\delta^{18} \mathrm{O}$ 值所指示的湿润 环境与高水位时期相对应.

在中亚北部，我们选择青海湖(季风边缘区，海拔 较高)、青土湖(位于东部)和博斯腾湖(位于中部)三个 典型的湖泊，来探索湖泊水位和气候特征的变化 (图7). 从青海湖的水位曲线和气候证据来看, 低水位 


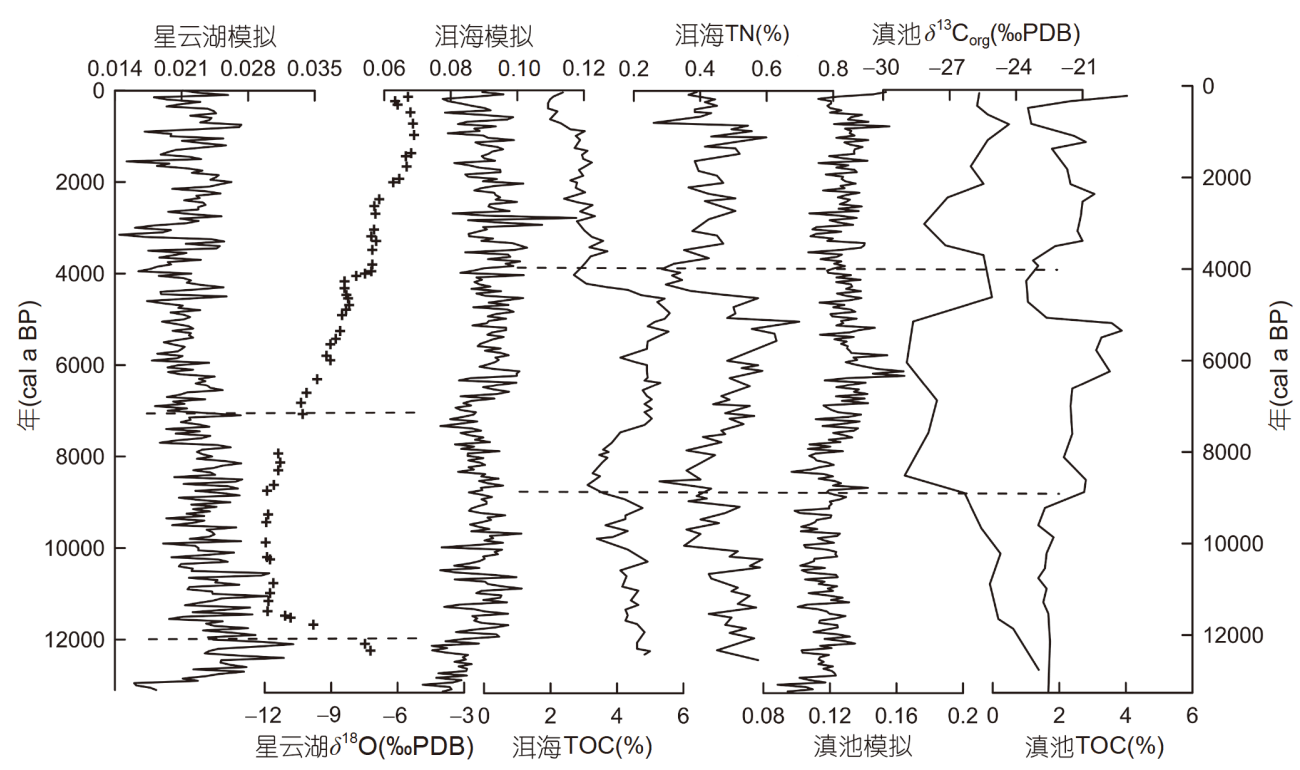

图 5 全新世中国南部模拟的典型湖泊水位与古气候记录对比

由左至右对应曲线为: 星云湖模拟的水位; 星云湖的 $\delta^{18} \mathrm{O}$ (Hodell等, 1999); 洱海模拟的水位; 洱海的TOC和TN (沈吉等, 2004); 滇池模拟的水 位; 滇池的 $\delta^{13} \mathrm{C}$ 和TOC( 吴艳宏等, 1998)

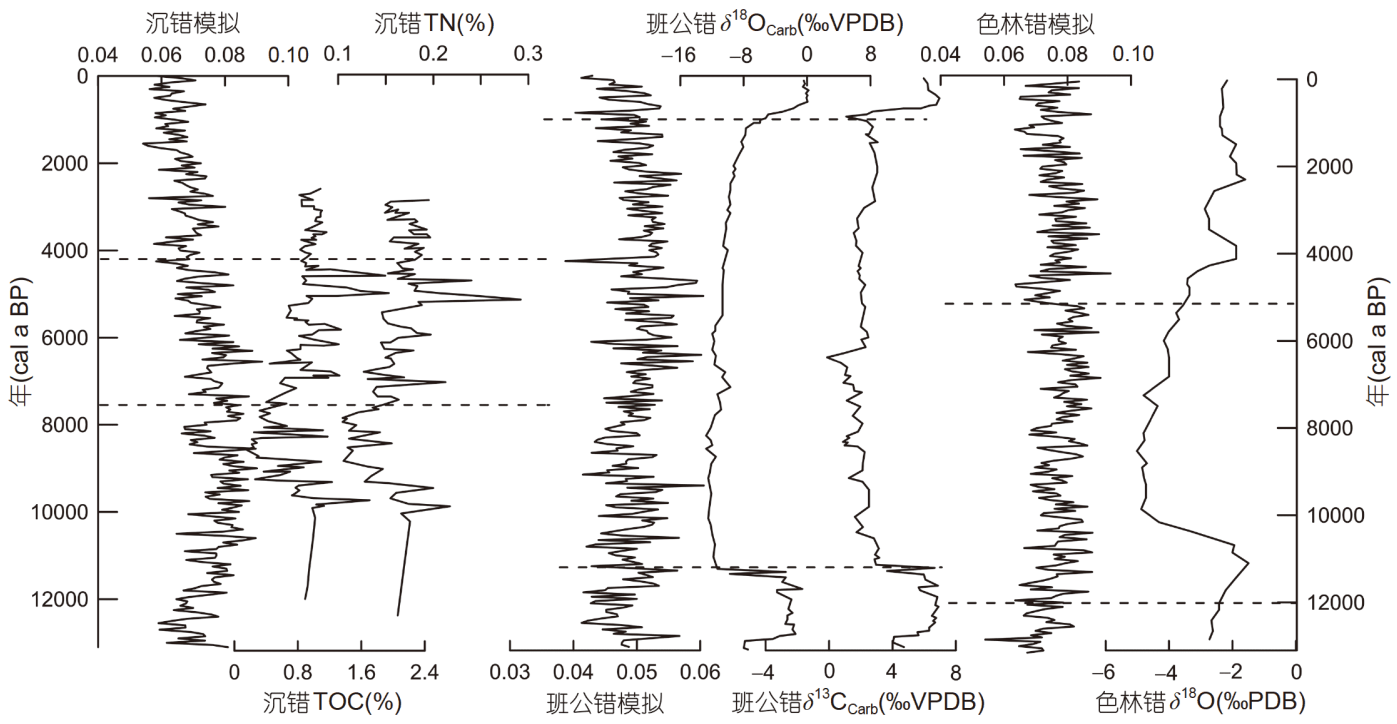

图 6 全新世青藏高原模拟的典型湖泊水位与古气候记录对比

由左至右对应曲线为: 沉错模拟的水位; Chen Co的TOC和 TN(Zhu等, 2009); 班公错模拟的水位; 班公错的 $\delta^{18} \mathrm{O}$ 和 $\delta^{13} \mathrm{C}($ 阳亚平, 2016); 色林错模 拟的水位; 色林错的 $\delta^{18} \mathrm{O}(\mathrm{Jin}$ 等, 2016)

出现在13000 11000 cal a BP，很有可能是受到新仙女 木冷事件的影响。之后，地区气候转暖。在 11000 8000 cal a BP的时间里, 伴随着气候变暖, 最高 的湖泊水位出现了. 青海湖地区气候条件比现代较暖 的时间止于 $4500 \mathrm{cal}$ a BP. 青土湖的模拟结果也与古气
候记录相吻合. 博斯腾湖水位与青土湖水位变化趋势 相似，在全新世中期呈明显的缓慢上升趋势，之后逐 渐下降. 虽然博斯腾湖的虚拟水位并没有出现急剧的 升高或下降情况，但其波动趋势与气候波动趋势是一 致的. 


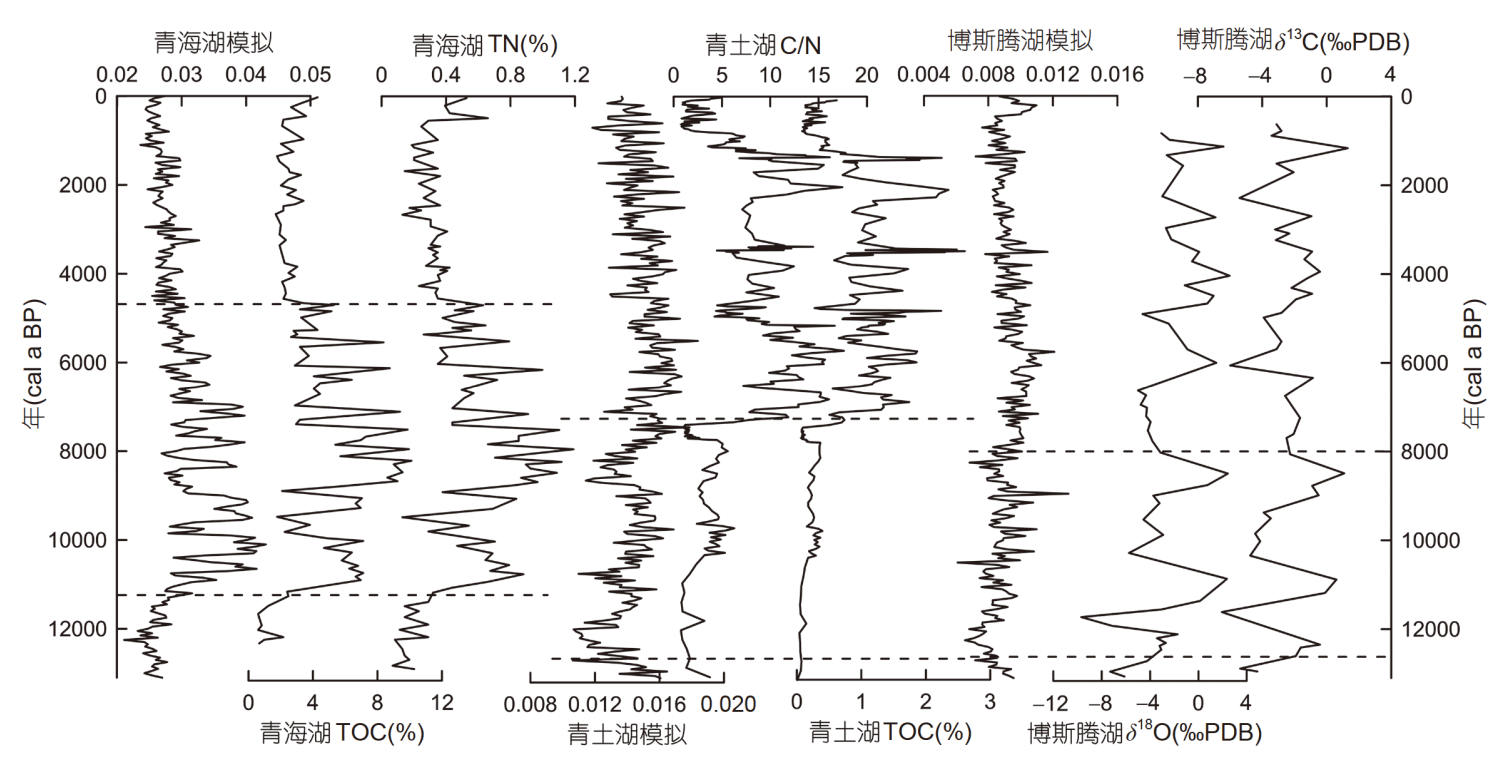

图 7 全新世中亚北部模拟的典型湖泊水位与古气候记录对比

由左至右对应曲线为: 青海湖模拟的水位; 青海湖的TOC和TN(Shen等, 2005a); 青土湖模拟的水位; 青土湖TOC和TN(李育和刘媛, 2017); 博斯 腾湖模拟的水位; 博斯腾湖的 $\delta^{18} \mathrm{O}($ Zhong和Xiong, 1998)

\section{4 讨论}

如上所述，东亚及中亚地区的气候主要受到西 风、印度夏季风和东亚夏季风环流系统的影响(安成 邦和陈发虎, 2009; Mishra等, 2015). 但是环流系统控 制的降水、蒸发、径流等气象要素在不同地理区域存 在差异(Morrill, 2004). 利用2.4部分的方法，本文考虑
了在决定区域水平衡变化中起决定性作用的因素, 并 讨论了驱动整个研究区域有效水分波动的影响机制. 将EOF应用于虚拟湖面模拟中，得到了第一模态的空 间分布和时间序列，第一模态贡献率为 $42 \%$. 从图 8 可 以看出，空间分布最显著的地区是中国北部、青藏高 原和中亚南部. 将空间分布与气象要素的空间变化、 模态的时间序列相结合, 发现最显著突出的区域与降
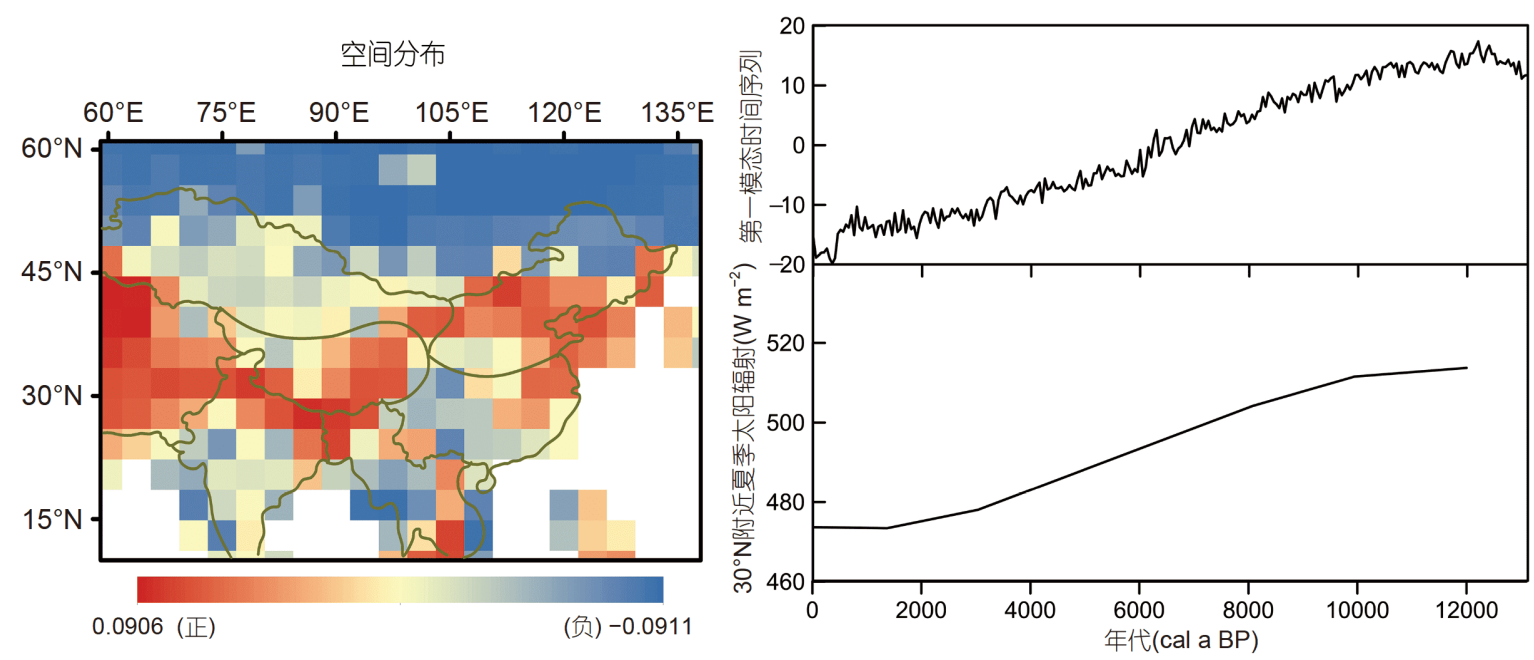

图 8 第一模态的空间分布和时间序列

红色(蓝色、黄色)表示该区域湖泊的影响因子与太阳辐射呈正相关(负相关、不相关) 
水显著减少的区域相同(图9a和10)。第一模态的时间 序列显示大部分地区的降水和夏季太阳辐射在全新世 期间表现出区域一致性的变化模式. 因此, 降水变化与 夏季太阳辐射变化的关系值得思考. 阿曼石笋中长时 间序列的 $\delta^{18} \mathrm{O}$ 变化通常遵循夏季太阳辐射变化. 这表 明在大约 $8000 \mathrm{cal}$ a BP之后, 北半球夏季太阳辐射的降 低导致了季风降水的逐渐减少(Fleitmann等, 2003; Wang等, 2005). 据此初步推测, 在全新世期间, 降水通 常遵循夏季太阳辐射的变化趋势.

根据模拟结果，我们证实了影响有效水分变化的 原因随着不同地区气象要素的变化而变化. 在中国北 部，尤其是东北地区全新世以来有效水分的减少，主 要是由于夏季太阳辐射减少引起的降水减少和温度升 高、大气辐射和短波辐射增强引起的湖泊蒸发增加的 共同影响(图9和10). 从图9c中可以看出，东北地区的 蒸发量增加最为强烈，由此可以看出，该地区蒸发量 对有效水分的影响要大于降水量. 在中国南部，降水 和蒸发在全新世有逐渐增加的趋势。在全新世晚期, 位于沿海地区的高水分更可能是由高海岸降水维持的 (图9和10). 在中亚北部，全新世有效水分的增加是由 于降水的增加和蒸发的减少共同影响。该地区气温也 呈上升趋势，但降水是影响该地区水汽变化的主要因
素，这可能是西风增强所导致的(图9和10). 而青藏高 原和中亚南部与中亚北部的变化趋势相反, 主要体现 在降水和蒸发的变化趋势上(图9和10). 这一现象表明, 青藏高原和中亚南部区域水汽波动的驱动机制主要是 夏季太阳辐射引起的亚洲季风的变化. 这些结果表明, 湖泊水量平衡不仅受西风、印度夏季风和东亚夏季风 主导的环流系统的控制, 而且重要的是要考虑气象要 素的区域特征.

根据瞬态气候演化实验的特点，本文模拟的虚拟 湖泊水位完全是自然状态下的水平衡演化过程，不涉 及人类活动. 而大部分古气候变化指标受全新世晚期 人类活动的影响(Zong等, 2010). 因此, 利用古气候记录 验证有效水分变化应以全新世早期和中期为主. $\mathrm{Li}$ 和 Morrill(2010)表明季风区湖泊水位在 $8.5 \mathrm{ka}$ 和 $6 \mathrm{ka}$ 时比PI 时相对较高主要是受到低蒸发和高降水的共同影响, 且 早全新世到中全新世增加的降水维持了中亚干旱区的 高湖面. 本研究表明, 在千年尺度上湖泊蒸发增加与降 水减少的共同作用是影响大部分季风区虚拟湖泊水位 下降的原因(沿海地区除外). 而千年尺度上增加的降水 是决定中亚北部虚拟湖泊水位变化的原因. 与以往的结 果相比, 我们的结论还表明, 蒸发和降水是区域有效水 分变化的主要原因, 并随时间和区域的变化而变化.
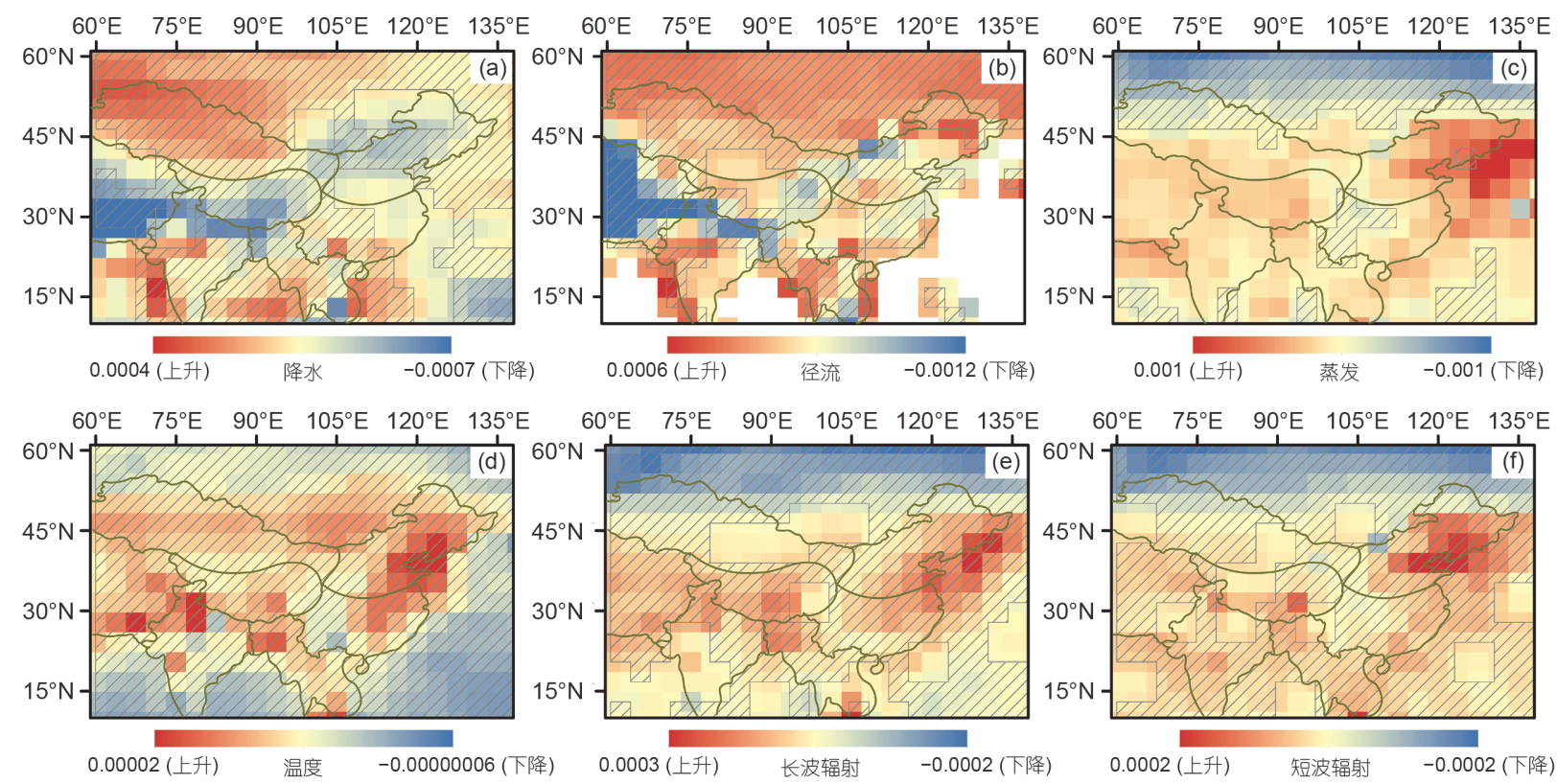

图 9 全新世降水 $(a) 、$ 径流 $(b) 、$ 蒸发 $(c)$ 、温度 $(d) 、$ 长波辐射 $(e) 、$ 短波辐射 $(f)$ 的变化趋势

红色(蓝色)表示全新世气象要素的上升(下降)趋势. 黄色表示这个区域没有明显的变化. 条带表示该区域显著性检验超过 $95 \%$ 

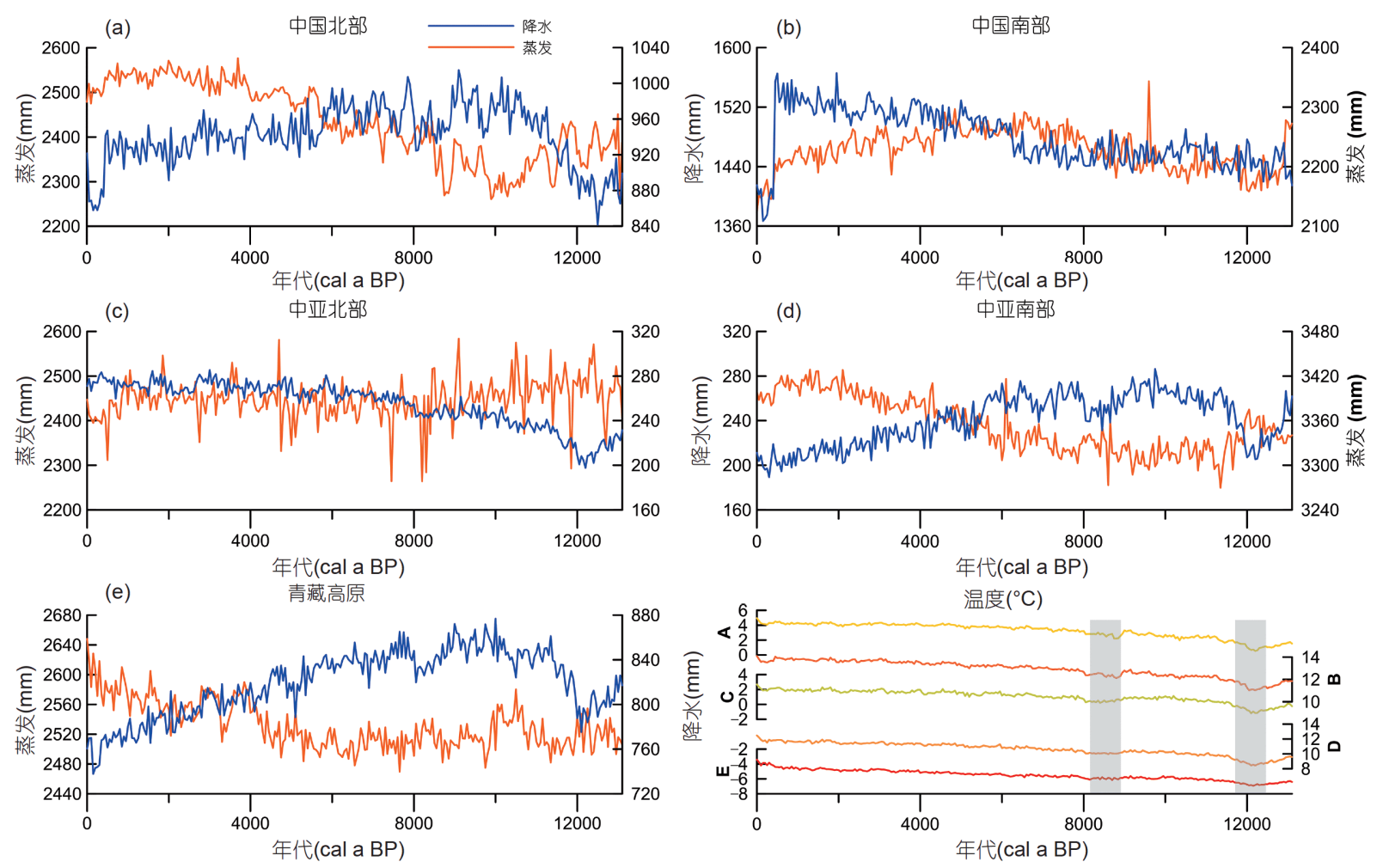

图 10 全新世区域平均降水、蒸发及温度变化的时间序列

此外, 所有地区 (中国北部、中国南部、中亚北 部、中亚南部和青藏高原)的气温都呈现上升趋势(图 10). 它显示了与新仙女木冷事件相关的温度降低, 随 后是全新世转暖. 但也在约 $8500 \sim 8000 \mathrm{cal} \mathrm{a} \mathrm{BP}$ 时存在 短暂的变冷期, 被称为“ $8.2 \mathrm{ka}$ ”事件. 该事件是由淡水 强迫引起的, 并与大西洋经向翻转环流的减弱有关 (Yan和Liu, 2019). 然而模拟的全新世气温整体呈上升 的模拟趋势并不代表该时期实际的变化趋势. 同时, 降 水量(蒸发量)总体呈下降(上升)趋势, 在新仙女木期和 “8.2ka”冷却期相对下降(增加). 这种模式与全新世时 期北半球气候变化特征相似(Ning等, 2019). 我们的研 究结果不仅证明了有效水分波动对气候变化和气象要 素变化的敏感性, 而且为全面了解千年尺度上有效水 分变化的驱动机制提供了新的方法.

\section{5 结论}

基于一系列湖泊模型, 我们对假设的湖泊水位变 化进行了连续模拟以追溯东亚及中亚地区全新世区域 有效水分的变化, 并探讨了不同地理区域水量平衡变
化的驱动机制. 在耦合大气、海洋环流模型的驱动下 的湖泊能量与水量平衡模型的模拟结果表明: 在全新 世期间, 中国北部、南部(沿海地区除外, 该地区的晚 全新世高水分是由高海岸降水维持的，可能是受到当 地海洋反馈的变化)、青藏高原和中亚南部的有效水 分呈逐渐减少趋势. 而中亚北部全新世有效水分的变 化有两种变化模式: 季风边缘区高水分出现在全新世 早期和中期, 西风区高水分出现在全新世晚期. 这些 结果在很大程度上与水分代理证据相一致. 此外, 我 们还得出结论, 中国北方有效水分的减少是逐渐增加 的湖泊蒸发和逐渐减少的降水共同作用的结果. 青藏 高原和中亚南部全新世有效水分的下降, 主要是由于 亚洲夏季风减弱导致降水减少的结果. 中亚北部有效 水分的增加是由西风环流加强引起的降水增加导 致的.

\section{参考文献}

安成邦, 陈发虎. 2009. 中东亚干旱区全新世气候变化的西风模式 —以湖泊研究为例. 湖泊科学, 21: 329-334

边彦明, 余佳, 邵兆刚, 韩建恩, 贺承广. 2013. 西藏佩枯错盆地晚更 
新世以来的狍粉组合特征及其古气候意义. 地球学报, 34: 87-94

崔美玲, 罗云利, 孙湘君. 2006. 吉林哈尼湖钻孔5000年以来的古植 被气候变化指示. 海洋地质与第四纪地质, 26: 117-122

陈发虎, 吴薇, 朱艳, Holmes J A, Madsen D B, 金明, Oviatt C G. 2004 阿拉善高原中全新世干旱事件的湖泊记录研究. 科学通报, 49: 1-9 胡刚, 王乃昂, 赵强, 程弘毅, 谌永生, 郭剑英. 2003. 花海湖泊特征时 期的水量平衡. 冰川冻土, 25: 485-490

侯光良, 鄂崇毅, 肖景义. 2012. 青藏高原全新世降水序列的集成重

建. 地理科学进展, 31: 1117-1123

介冬梅, 吕金福, 李志民, 冷雪天, 王升忠, 张桂荣. 2001. 大布苏湖全 新世沉积岩心的碳酸盐含量与湖面波动. 海洋地质与第四纪地 质, 21: 77-82

李育, 刘媛. 2016. 末次盛冰期以来中国湖泊记录对环流系统及气候 类型的响应. 地理学报, 71: 1898-1910

李育, 刘媛. 2017. 干旱区内流河流域长时间尺度水循环重建与模拟 —以石羊河流域为例. 地球科学进展, 32: 731-743

李育, 王岳, 张成琦, 周雪花, 王乃昂. 2014. 干旱区内陆河流域中游 地区全新世沉积相变与环境变化一一石羊河流域为例. 地理 研究, 33: 1866-1880

李文渏, 姚祖驹. 1993. 中国北中亚热带晚第四纪植被与环境研究. 北京: 海洋出版社. 54-61

马春梅, 朱诚, 郑朝贵, 武春林, 关勇, 赵志平, 黄林燕, 黄润. 2008. 晚 冰期以来神农架大九湖泥炭高分辨率气候变化的地球化学记录 研究. 科学通报, 53(增刊 I ): 26-37

沈吉. 2012. 末次盛冰期以来中国湖泊时空演变及驱动机制研究综

述: 来自湖泊沉积的证据. 科学通报, 57: 3228-3242

沈吉, 吴瑞金, 安芷生. 1998. 大布苏湖沉积剖面有机碳同位素特征 与古环境. 湖泊科学, 10: 8-10

沈吉, 杨丽原, 羊向东, R.Matsumoto, 童国榜, 朱育新, 张振克, 王苏 民. 2004. 全新世以来云南洱海流域气候变化与人类活动的湖泊 沉积记录. 中国科学 D辑: 地球科学 34: 130-138

唐领余. 1992. 云南敌海地区四万年以来植被史与气候. 微体古生物 学报, 9: 433-455

吴健, 沈吉. 2010a. 兴凯湖沉积粒度特征揭示的 $27.7 \mathrm{ka}$ BP以来区域 古气候演变. 湖泊科学, 22: 110-118

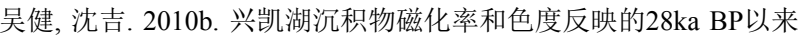
区域古气候环境演化. 海洋地质与第四纪地质, 28: 365-372

吴艳宏, 吴瑞金, 薛滨, 钱君龙, 肖家仪. 1998. 13ka BP以来滇池地区 古环境演化. 湖泊科学, 10: 5-9

吴中海, 赵希涛, 吴珍汉, 胡道功, 马志邦, 叶培盛, 江万. 2005. 西藏 安多-错那湖地堑的第四纪地质、断裂活动及其运动学特征分 析. 第四纪研究, 25: 490-502

喻春霞, 罗运利, 孙湘君. 2008. 吉林柳河哈尼湖13.1 4.5cal ka BP古 气候演化的高分辨率狍粉记录. 第四纪研究, 28: 929-938

阳亚平. 2016. 末次冰消期以来西藏班公错沉积物记录的气候与环 境变化. 硕士学位论文. 兰州: 兰州大学. 1-69
游海涛, 刘嘉麒. 2012. 14ka BP以来二龙湾玛珥湖沉积物记录的高 分辨率气候演变. 科学通报, 57: 2322-2329

赵强, 王乃昂, 李秀梅, 程弘毅, 李育, 李钢. 2005. 青土湖地区9500a BP以来的环境变化研究. 冰川冻土, 27: 352-359

赵希涛, 赵元艺, 郑绵平, 马志邦, 曹建科, 李明慧. 2001. 班戈错晚第 四纪湖泊发育、湖面变化与藏北高原东南部末次大湖期湖泊演 化. 地球学报, 32: 13-26

周静, 王苏民, 吕静. 2003. 洱海地区一万多年以来气候环境演化的 湖泊沉积记录. 湖泊科学, 15: 104-111

Anderson L, Abbott M B, Finney B P, Edwards M E. 2005. Palaeohydrology of the Southwest Yukon Territory, Canada, based on multiproxy analyses of lake sediment cores from a depth transect. Holocene, 15: 1172-1183

Anderson L, Finney B P, Shapley M D. 2011. Lake carbonate- $\delta^{18} \mathrm{O}$ records from the Yukon Territory, Canada: Little Ice Age moisture variability and patterns. Quat Sci Rev, 30: 887-898

Benson L V, Paillet F L. 1989. The use of total lake-surface area as an indicator of climatic change: Examples from the Lahontan Basin. Quat Res, 32: 262-275

Berger A L. 1978. Long-term variations of caloric insolation resulting from the Earth's orbital elements. Quat Res, 9: 139-167

Berger A, Loutre M F. 1991. Insolation values for the climate of the last 10 million years. Quat Sci Rev, 10: 297-317

Boomer I, Aladin N, Plotnikov I, Whatley R. 2000. The palaeolimnology of the Aral Sea: A review. Quat Sci Rev, 19: 1259-1278

Brenner M, Dorsey K, Song X L, Wang Z G, Long R H, Binford M W, Whitmore T J, Moore A M. 1991. Paleolimnology of Qilu Hu, Yunnan province, China. Hydrobiologia, 214: 333-340

Cheng J, Liu Z Y, He F, Otto-Bliesner B, Brady E, Lynch-Stieglitz J. 2014. Model-proxy comparison for overshoot phenomenon of Atlantic thermohaline circulation at Bølling-Allerød. Chin Sci Bull, 59: $4510-4515$

Davis M, Douglas C, Calcote R, Cole K L, Winkler M G, Flakne R. 2000. Holocene climate in the Western Great Lakes National Parks and Lakeshores: Implications for future climate change. Conserv Biol, 14: 968-983

Dickinson R E, Henderson-Sellers A, Kennedy P J. 1993. NCAR Technical Notes

Dickson D R, Yepsen J H, Vern Hales J. 1965. Saturated vapor pressures over Great Salt Lake brine. J Geophys Res, 70: 500-503

Ferronskii V I, Polyakov V A, Brezgunov V S, Vlasova L S, Karpychev Y A, Bobkov A F, Romaniovskii V V, Johnson T, Ricketts D, Rasmussen K. 2003. Variations in the hydrological regime of KaraBogaz-Gol Gulf, Lake Issyk-Kul, and the Aral Sea assessed based on data of bottom sediment studies. Water Resour, 30: 252-259

Fleitmann D, Burns S J, Mudelsee M, Neff U, Kramers J, Mangini A, 
Matter A. 2003. Holocene forcing of the Indian Monsoon recorded in a stalagmite from Southern Oman. Science, 300: 1737-1739

Rossit C A, Laura P A A, Bambill D, Fontes J C, Gasse F, Gibert E. 1996. Holocene environmental changes in Lake Bangong basin (Western Tibet). Part 1: Chronology and stable isotopes of carbonates of a Holocene lacustrine core. Palaeogeogr Palaeoclimatol Palaeoecol, 120: 25-47

Hodell D A, Brenner M, Kanfoush S L, Curtis J H, Stoner J S, Song X L, Wu Y, Whitmore T J. 1999. Paleoclimate of Southwestern China for the past $50000 \mathrm{yr}$ inferred from lake sediment records. Quat Res, 52: $369-380$

He F. 2011. Simulating Transient Climate Evolution of the Last Deglaciation with CCSM 3. Doctoral Dissertation. Madison: University of Wisconsin

He F, Shakun J D, Clark P U, Carlson A E, Liu Z Y, Otto-Bliesner B L, Kutzbach J E. 2013. Northern Hemisphere forcing of Southern Hemisphere climate during the last deglaciation. Nature, 494: 81-85

Hostetler S W, Bartlein P J. 1990. Simulation of lake evaporation with application to modeling lake level variations of Harney-Malheur Lake, Oregon. Water Resour Res, 26: 2603-2612

Hostetler S W, Small E E. 1999. Response of North American freshwater lakes to simulated future climates. J Am Water Resour Assoc, 35: 1625-1637

Innes J L. 1991. High-altitude and high-latitude tree growth in relation to past, present and future global climate change. Holocene, 1: 168173

Jiang W Y, Guo Z T, Sun X J, Wu H B, Chu G Q, Yuan B Y, Christine H, Joel G. 2006. Reconstruction of climate and vegetation changes of Lake Bayanchagan (Inner Mongolia): Holocene variability of the East Asian monsoon. Quat Res, 65: 411-420

Jin C F, Günther F, Li S J, Jia G D, Peng P A, Gleixner G. 2016. Reduced early Holocene moisture availability inferred from $\delta \mathrm{D}$ values of sedimentary $n$-alkanes in Zigetang Co, Central Tibetan Plateau. Holocene, 26: 556-566

Joos F, Spahni R. 2008. Rates of change in natural and anthropogenic radiative forcing over the past 20000 years. Proc Natl Acad Sci USA, 105: 1425-1430

Kundu P K, Allen J S. 1976. Some three-dimensional characteristics of low-frequency current fluctuations near the Oregon coast. J Phys Oceanogr, 6: 181-199

Li C H, Wu Y H, Hou X H. 2011. Holocene vegetation and climate in Northeast China revealed from Jingbo Lake sediment. Quat Int, 229: $67-73$

Li D W, Li Y K, Ma B Q, Dong G C, Wang L Q, Zhao J X. 2009. Lakelevel fluctuations since the Last Glaciation in the Selin Co (Lake), Central Tibet, investigated using optically stimulated luminescence dating of beach ridges. Environ Res Lett, 4: 1-10

Li X Z, Liu X J, He Y X, Liu W G, Zhou X, Wang Z. 2018. Summer moisture changes in the Lake Qinghai area on the northeastern Tibetan Plateau recorded from a meadow section over the past 8400 yrs. Glob Planet Change, 161: 1-9

Li Y, Morrill C. 2010. Multiple factors causing Holocene lake-level change in monsoonal and arid central Asia as identified by model experiments. Clim Dyn, 35: 1119-1132

Li Y, Morrill C. 2013. Lake levels in Asia at the Last Glacial Maximum as indicators of hydrologic sensitivity to greenhouse gas concentrations. Quat Sci Rev, 60: 1-12

Liu X Q, Herzschuh U, Shen J, Jiang Q F, Xiao X Y. 2008a. Holocene environmental and climatic changes inferred from Wulungu Lake in northern Xinjiang, China. Quat Res, 70: 412-425

Liu X Q, Dong H L, Jason A R, Matsumoto R, Bo Y, Wang Y B. 2008b. Evolution of Chaka Salt Lake in NW China in response to climatic change during the Latest Pleistocene-Holocene. Quat Sci Rev, 27: $867-879$

Liu Z Y, Otto-Bliesner B L, He F, Brady E C, Tomas R, Clark P U, Carlson A E, Lynch-Stieglitz J, Curry W, Brook E J, Erickson D, Jacob R, Kutzbach J, Cheng J. 2009. Transient simulation of last deglaciation with a new mechanism for bølling-allerød warming. Science, 325: 310-314

Luoto T P, Sarmaja-Korjonen K. 2011. Midge-inferred Holocene effective moisture fluctuations in a subarctic lake, northern Lapland. Boreas, 40: 650-659

Madsen D B, Haizhou M, Rhode D, Brantingham P J, Forman S L. 2008. Age constraints on the Late Quaternary evolution of Qinghai Lake, Tibetan Plateau. Quat Res, 69: 316-325

Mishra P K, Anoop A, Schettler G, Prasad S, Jehangir A, Menzel P, Naumann R, Yousuf A R, Basavaiah N, Deenadayalan K, Wiesner M G, Gaye B. 2015. Reconstructed late Quaternary hydrological changes from Lake Tso Moriri, NW Himalaya. Quat Int, 371: 76-86

Morrill C. 2004. The influence of Asian summer monsoon variability on the water balance of a Tibetan lake. J Paleolimnol, 32: 273-286

Morrill C, Small E E, Sloan L C. 2001. Modeling orbital forcing of lake level change: Lake Gosiute (Eocene), North America. Glob Planet Change, 29: 57-76

Ning L, Liu J, Bradley R S, Yan M. 2019. Comparing the spatial patterns of climate change in the 9th and 5th millennia BP from TRACE-21 model simulations. Clim Past, 15: 41-52

Peltier W R. 2004. Global glacial isostasy and the surface of the ice-age Earth: The ICE-5G (VM 2) model and GRACE. Annu Rev Earth Planet Sci, 32: 111-149

Pollard D, Schulz M. 1994. A model for the potential locations of Triassic evaporite basins driven by paleoclimatic GCM simulations. 
Glob Planet Change, 9: 233-249

Qin B Q, Yu G. 1998. Implications of lake level variations at 6 ka and $18 \mathrm{ka}$ in mainland Asia. Glob Planet Change, 18: 59-72

Rahmstorf S, Crucifix M, Ganopolski A, Goosse H, Kamenkovich I, Knutti R, Lohmann G, Marsh R, Mysak L A, Wang Z, Weaver A J. 2005. Thermohaline circulation hysteresis: A model intercomparison. Geophys Res Lett, 32: 1-5

Ricketts R D, Johnson T C, Brown E T, Rasmussen K A, Romanovsky V V. 2001. The Holocene paleolimnology of Lake Issyk-Kul, Kyrgyzstan: Trace element and stable isotope composition of ostracodes. Palaeogeogr Palaeoclimatol Palaeoecol, 176: 207-227

Sharma A, Huang H P, Zavialov P, Khan V. 2018. Impact of desiccation of Aral Sea on the regional climate of central Asia using WRF model. Pure Appl Geophys, 175: 465-478

Sevastyanov D V, Smirnova N P. 1986. Issik Kul Lake and Tendency of its Natural Development (in Russian). Leningrad: Nauka. 256

Sevastyanov D V, Dorofeyuk N I. 1992. The history of the water ecosystem of Mongolia (in Russian). Izv Vses Geogr Obshch, 124: $123-138$

Shen J, Liu X Q, Wang S M, Matsumotob R. 2005a. Palaeoclimatic changes in the Qinghai Lake area during the last 18000 years. Quat Int, 136: 131-140

Stommel H. 1961. Thermohaline convection with two stable regimes of flow. Tellus, 13: 224-230

Sun Q L, Wang S M, Zhou J, Cheng Z Y, Shen J, Xie X P, Wu F, Chen P. 2010. Sediment geochemistry of Lake Daihai, north-central China: Implications for catchment weathering and climate change during the Holocene. J Paleolimnol, 43: 75-87

Sun Q L, Wang S M, Zhou J, Shen J, Chen P, Xie X P, Wu F. 2009. Lake surface fluctuations since the late glaciation at Lake Daihai, North central China: A direct indicator of hydrological process response to East Asian monsoon climate. Quat Int, 194: 45-54

Tarasov P E, Kremenetskii K V. 1995. Geochronology and stratigraphy of the Holocene lacustrine-bog deposits in northern and central Kazakhstan. Stratigr Geol Correl, 3: 73-80

Wang L, Rioual P, Panizzo V N, Lu H Y, Gu Z Y, Chu G Q, Yang D G, Han J T, Liu J Q, Mackay A W. 2012. A 1000-yr record of environmental change in NE China indicated by diatom assemblages from maar lake Erlongwan. Quat Res, 78: 24-34

Wang W, Feng Z D. 2013. Holocene moisture evolution across the Mongolian Plateau and its surrounding areas: A synthesis of climatic records. Earth-Sci Rev, 122: 38-57

Wang W, Feng Z D, Ran M, Zhang C J. 2013. Holocene climate and vegetation changes inferred from pollen records of lake Aibi, northern Xinjiang, China: A potential contribution to understanding of Holocene climate pattern in East-central Asia. Quat Int, 311: 54-62
Wang Y B, Bekeschus B, Handorf D, Liu X Q, Dallmeyer A, Herzschuh U. 2017. Coherent tropical-subtropical Holocene see-saw moisture patterns in the Eastern Hemisphere monsoon systems. Quat Sci Rev, 169: $231-242$

Wang Y, Cheng H, Edwards R L, He Y Q, Kong X G, An Z S, Wu J Y, Kelly M J, Dykoski C A, Li X D. 2005. The Holocene Asian Monsoon: Links to solar changes and North Atlantic climate. Science, 308: 854-857

Weare B C, Newell R E. 1977. Empirical orthogonal analysis of atlantic ocean surface temperatures. Q J R Met Soc, 103: 467-478

Wen R L, Xiao J L, Chang Z G, Zhai D Y, Xu Q H, Li Y C, Itoh S, Lomtatidze Z. 2010. Holocene climate changes in the mid-highlatitude-monsoon margin reflected by the pollen record from Hulun Lake, northeastern Inner Mongolia. Quat Res, 73: 293-303

Wünnemann B, Mischke S, Chen F H. 2006. A Holocene sedimentary record from Bosten Lake, China. Palaeogeogr Palaeoclimatol Palaeoecol, 234: 223-238

Wu X D, Zhang Z H, Xu X M, Shen J. 2012. Asian summer monsoonal variations during the Holocene revealed by Huguangyan maar lake sediment record. Palaeogeogr Palaeoclimatol Palaeoecol, 323-325: $13-21$

Xiao J L, Chang Z G, Wen R L, Zhai D Y, Itoh S, Lomtatidze Z. 2009. Holocene weak monsoon intervals indicated by low lake levels at Hulun Lake in the monsoonal margin region of northeastern Inner Mongolia, China. Holocene, 19: 899-908

Xiao J L, Xu Q H, Nakamura T, Yang X L, Liang W D, Inouchi Y. 2004. Holocene vegetation variation in the Daihai Lake region of north-central China: A direct indication of the Asian monsoon climatic history. Quat Sci Rev, 23: 1669-1679

Xue B, Yu G. 2010. Changes of atmospheric circulation since the last interstadial as indicated by the lake-status record in China. Acta Geol Sin-Engl Ed, 74: 836-845

Yan M, Liu J. 2019. Physical processes of cooling and mega-drought during the $4.2 \mathrm{ka}$ BP event: Results from TraCE-21 ka simulations. Clim Past, 15: 265-277

Yang H J, Zhao Y Y, Liu Z Y, Li Q, He F, Zhang Q. 2015. Heat transport compensation in atmosphere and ocean over the past 22000 years. Sci Rep, 5: 16661

Yao J Q, Chen Y N, Zhao Y, Yu X J. 2018. Hydroclimatic changes of Lake Bosten in Northwest China during the last decades. Sci Rep, 8: 9118

Zhai D Y, Xiao J L, Zhou L, Wen R L, Chang Z G, Wang X, Jin X D, Pang Q Q, Itoh S. 2011. Holocene East Asian monsoon variation inferred from species assemblage and shell chemistry of the ostracodes from Hulun Lake, Inner Mongolia. Quat Res, 75: 512522 
Zhang E L, Wang Y B, Sun W W, Shen J. 2016. Holocene Asian monsoon evolution revealed by a pollen record from an alpine lake on the southeastern margin of the Qinghai-Tibetan Plateau, China. Clim Past, 12: 415-427

Zhang S R, Xiao J L, Xu Q H, Wen R L, Fan J W, Huang Y, Yamagata H. 2018. Differential response of vegetation in Hulun Lake region at the northern margin of Asian summer monsoon to extreme cold events of the last deglaciation. Quat Sci Rev, 190: 57-65

Zhang Y, Gao X, Zhong Z Y, Chen J, Peng B Z. 2009. Sediment accumulation of Dianchi Lake determined by ${ }^{137} \mathrm{Cs}$ dating. J Geogr Sci, 19: 225-238

Zhao Y T, An C B, Mao L M, Zhao J J, Tang L Y, Zhou A F, Li H, Dong W M, Duan F T, Chen F H. 2015. Vegetation and climate history in arid western China during MIS2: New insights from pollen and grain-size data of the Balikun Lake, eastern Tien Shan. Quat Sci Rev, 126: 112-125

Zheng Y H, Pancost R D, Naafs B D A, Li Q Y, Liu Z, Yang H. 2018. Transition from a warm and dry to a cold and wet climate in NE China across the Holocene. Earth Planet Sci Lett, 493: 36-46

Zhong W, Xiong H G. 1998. Isotopic evidence for Holocene climatic changes in Bosten Lake, Southern Xinjiang, China. Chin Geogr Sci, 8: $176-182$

Zhu L P, Zhen X L, Wang J B, Lv H Y, Xie M P, Kitagawa H, Possnert G. 2009. A 30000-year record of environmental changes inferred from Lake Chen Co, Southern Tibet. J Paleolimnol, 42: 343-358

Zong Y Q, Yu F L, Huang G Q, Lioyd J M, Yim W W S. 2010. Sedimentary evidence of Late Holocene human activity in the Pearl River delta, China. Earth Surf Process Landforms, 35: 1095-1102

(责任编委: 刘晓东) 